\title{
Cognitive deficits and self-care behaviors in elderly adults with heart failure
}

\author{
This article was published in the following Dove Press journal: \\ Clinical Interventions in Aging \\ 3 October 2017 \\ Number of times this article has been viewed
}

\author{
Izabella Uchmanowicz' \\ Beata Jankowska-Polańska' \\ Grzegorz Mazur ${ }^{2}$ \\ Erika Sivarajan Froelicher ${ }^{3,4}$ \\ 'Department of Clinical Nursing, \\ Faculty of Health Sciences, Wroclaw \\ Medical University, Wroclaw, Poland; \\ ${ }^{2}$ Department and Clinic of Internal \\ and Occupational Diseases and \\ Hypertension, Wroclaw Medical \\ University, Wrocław, Poland; \\ ${ }^{3}$ Department of Physiological Nursing, \\ School of Nursing; ${ }^{4}$ Department of \\ Epidemiology \& Biostatistics, School \\ of Medicine, University of California \\ San Francisco, San Francisco, CA, USA
}

Correspondence: Izabella Uchmanowicz Department of Clinical Nursing, Faculty of Health Sciences, Wroclaw Medical University, 5 Bartla Street, 5I-6I8

Wroclaw, Poland

Tel +48 7। $784 \quad 1824$

Fax +48713459324

Email izabella.uchmanowicz@umed. wroc.pl
Introduction: Elderly adults with heart failure (HF) may have problems with self-care behaviors because of cognitive deficits. Self-care deficits have been found to be significantly associated with negative health care outcomes among HF patients. The aim of this paper was to assess cognitive deficits and the level of self-care ability in elderly patients with HF, and to determine if a relationship exists between cognitive deficits and self-care.

Materials and methods: The study included 270 elderly patients (mean age: 72.5 years) with HF. We used the Mini Mental State Examination Scale (MMSE) to evaluate cognitive functioning, and the European Heart Failure Self-care Behavior Scale, revised into a nine-item scale (EHFScBS-9), to evaluate self-care behaviors. Associations between the variables were examined using multiple regression analysis.

Results: Lower scores in both MMSE and EHFScBS-9 questionnaires were correlated with older age, living alone, lower education, longer duration of illness, higher number of rehospitalizations, as well as lower left ventricular ejection fraction and higher New York Heart Association (NYHA) class. The multiple regression analysis was used for evaluation of the impact of the following predictors: MMSE score, age, duration of illness, ejection fraction, number of hospitalizations, sex, residence, education, relationship status, and NYHA class on EHFScBS-9 score.

Conclusions: Elderly patients with HF may have worse self-care behaviors because of their cognitive deficits. Age was the strongest predictor of worse MMSE scores. Multidisciplinary health teams should pay attention to the special needs of elderly patients who live with their illness for many years and have no social support because of living alone.

Keywords: self-care behaviors, aging care

\section{Introduction}

Heart failure (HF) is a major health issue in developed countries. It is estimated that in Europe and North America, chronic HF occurs in 1\%-2\% of the adult population, 1,2 while 0.8 million people suffer from HF in Poland. ${ }^{3}$ Diminished cognitive function affects $25 \%-50 \%$ of patients with HF; patients with cognitive dysfunction have less knowledge about their disease than those with intact cognitive function. ${ }^{4}$

Elderly patients with HF have a significantly increased prevalence of dementia and mild cognitive impairment, compared with people of similar age without HF. ${ }^{5-7}$ Studies describing cognitive impairment in HF patients have estimated prevalence at anywhere between $30 \%$ and $80 \%{ }^{8}$ Some data show that the incidence varies widely from $25 \%$ to about $70 \%-80 \%$, depending on the characteristics of the sample and of the disease, the instruments used to assess cognition and study design.9,10

Petrucci et $\mathrm{al}^{11}$ demonstrated that cognitive deficits are common in advanced $\mathrm{HF}$ and worsen with increasing severity of HF; however, more severe deficits in patients with earlier implantation of mechanical cardiac assist devices were found. 
Also, Kozdağ et al ${ }^{12}$ reported improvement in all domains of cognitive functions except verbal and visual memory tests as the effect of enhanced external counterpulsation.

The significant role of physical activity in the determination of cognitive impairment in HF was investigated by Alosco et $\mathrm{al}^{13}$ who showed that lower physical activity predicted worse cognition and cerebral perfusion 12 months later in HF and concluded that physical inactivity in HF may contribute to cognitive impairment and exacerbate risk for conditions such as Alzheimer's disease.

Cognitive decline in HF often presents deficits in cognition that affect, for example, attention, memory, executive function, language, and psychometric speed. Therefore, age-related cognitive dysfunction may affect patients' self-care capabilities. ${ }^{14}$

Riegel et a ${ }^{15}$ defined self-care as a naturalistic decisionmaking process that patients use in the choice of behaviors that maintain physiological stability and the response to symptoms when they occur. HF-related self-care behaviors are important in optimizing outcomes for patients with HF. Lainsack et al ${ }^{16}$ also stressed that adequate self-care behavior related to HF reflects the actions that a patient undertakes to maintain healthy functioning and well-being. ${ }^{17}$ Patients who are actively involved in their own care and treatment, and who adhere to the regimen prescribed, are found to have improved survival and fewer readmissions..$^{18,19}$

Self-care strategies may present a problem for elderly patients with HF, as they involve behaviors such as taking medication, monitoring and interpreting symptoms, keeping appointments, and contacting a nurse or a physician in case of exasperation. Therefore, nursing care should be individualized and adjusted to the cognitive capabilities of an elderly HF patient.

In earlier studies, diminished cognition has been shown to be associated with poor HF self-care. ${ }^{20}$ Self-care also involves making health-related decisions. Thus, the assessment of cognitive deficits may play an important part in evaluating patients' educational needs, adaptability, and adherence capabilities in terms of self-care in HF.

The study objectives were to assess cognitive deficits and the level of self-care in elderly patients with HF, to determine the correlation between cognitive deficits and self-care, and to determine which variables influence self-care behaviors and cognitive deficits.

\section{Materials and methods Study design}

A cross-sectional study was used to achieve the study objectives. Sample size estimates were used to assess whether there is a correlation between cognitive deficits and the level of selfcare ability in elderly patients with HF. Assuming a two-sided test with alpha $=0.06$, beta $=0.10$, and the ability to detect $r=0.20$ would require a sample size of 259 according to Hulley et al. ${ }^{21}$ We opted to recruit 270 subjects to accommodate incomplete data on one or both of the study variables.

\section{Participants}

The study was performed in a Cardiology Clinic in Wrocław, Poland. A group of 270 elderly patients (138 women and 132 men), diagnosed with chronic HF, participated in this study. The mean age was 72.5 years ( $\mathrm{SD} \pm 8.23$ ), the mean duration of illness was 6 years ( $\mathrm{SD} \pm 4.76)$, the mean number of hospitalizations in the previous years was 2.13 ( $\mathrm{SD} \pm 1.69$ ), as well as the mean ejection fraction was $44.64 \%$ ( $\mathrm{SD} \pm 11.7)$.

The inclusion criteria were as follows: 1) clinically confirmed HF diagnosis, 2) the patient's written informed consent, 3) age over 65 years. Exclusion criteria were as follows: 1) requirement for intensive cardiac care, 2) history of stroke. The study was approved by the Bioethics Committee of Wrocław Medical University (No KB-67/2016).

\section{Measurements}

Demographic and sociodemographic data (age, sex, education level, and relationship status) were obtained from interviews performed by a cardiac nurse and from patient records. Clinical data, such as the New York Heart Association (NYHA) functional class, left ventricular ejection fraction (LVEF), number of rehospitalizations, and the duration of the disease, were obtained from records and from personal interviews performed by a cardiac nurse.

Patients completed questionnaires - the Mini Mental State Examination Scale (MMSE) to evaluate cognitive functioning, and the European Heart Failure Self-care Behavior Scale, revised into a nine-item scale (EHFScBS-9), to evaluate self-care behaviors. ${ }^{22,23}$

\section{Mini Mental State Examination Scale}

The MMSE is a very brief, easily administered mental status examination that has proven a highly reliable and valid instrument for detecting and tracking the progression of cognitive impairment associated with neurodegenerative diseases. Consequently, MMSE is the most widely used mental status examination in the world. The maximum MMSE score is 30 . The cutoff scores of 24-25 provide a likelihood of memory problems and the MMSE has shown high reliability and validity. ${ }^{22,23}$

\section{Self-reported self-care (EHFScBS-9)}

Self-reported maintenance behaviors were measured using the nine-item version of the EHFScBS-9, Polish version. ${ }^{24,25}$ 
This questionnaire was based on a theoretical construct of self-care by Orem. ${ }^{26}$ In the present study, we used EHFScBS-9, which includes nine questions related to various aspects of self-care, including daily control of weight, level of physical activity, use of a low-sodium diet, amount of ingested fluids, self-monitoring, and appropriate reaction to potential symptoms of decompensation. ${ }^{27}$ The EHFScBS- 9 currently has a scoring scale from 9 to 45 , with higher scores indicating worse self-care. A standardized score between 0 and 100, with higher scores indicating better self-care, can make interpretation of the score easier. The instrument has documented strong psychometric properties based on many populations and culture groups, and has been adapted and translated into numerous languages. ${ }^{28,29}$

\section{Statistical analysis}

The analyses were performed using the R software, version 3.3.0. Comparisons of two groups were performed using Student's $t$-test (for normal distributions of a variable in the groups analyzed) or the Mann-Whitney test (for distributions other than normal).

Multiple regression analysis included factors predictors affecting EHFScB-9 score: MMSE score, age, duration of illness, ejection fraction, number of hospitalizations, sex, residence, education, relationship status, and NYHA class. The results were considered significant with $p$-values $<0.05$.

Comparisons between three or more groups were performed using analysis of variance (for normal distributions of a variable in the groups analyzed) or the Kruskal-Wallis test (for distributions other than normal). When a comparison showed statistically significant differences, post hoc analyses were performed: Tukey's honest significant difference test (for normal distributions) or the Mann-Whitney test with Bonferroni correction (for distributions other than normal). Correlations between two non-normally distributed groups were analyzed using Pearson's or Spearman's coefficients.

Correlation analyses are interpreted as follows: $|r| \geq 0.9-$ very strong correlation; $0.7 \leq|\mathrm{r}|<0.9$ - strong correlation; $0.5 \leq|\mathrm{r}|<0.7$ - moderately strong correlation; $0.3 \leq|\mathrm{r}|<0.5-$ weak correlation; $|\mathrm{r}| \geq 0.3$ - very weak (negligible) correlation.

The interpretation model was adopted from Hinkle et al. ${ }^{30}$ Variable distribution normality was verified using the Shapiro-Wilk test. All analyses used a significance level; $p$-values $<0.05$ were interpreted as statistically significant.

\section{Ethics approval}

The study protocol was approved by the Independent Bioethics Committee of the Wroclaw Medical University (decision no KB-67/2016). All participants gave written informed consent after thorough explanation of the procedures involved. The study was carried out in accordance with the tenets of the Declaration of Helsinki.

\section{Results \\ Patients' characteristics}

The study included 270 patients (138 women, 132 men), mean age 72.57 years $( \pm 8.23)$. The patients' basic sociodemographic and clinical characteristics are shown in Table 1.

Analysis of the respondents' marital status showed that $56.67 \%(n=153)$ were in relationships, while $43.33 \%$ were single. Nearly half of the patients, $49.26 \%$, had had primary or vocational education. While $33.33 \%$ were high-school educated, $17.41 \%$ were university- or college educated.

The patients studied had different clinical characteristics. Most patients - 41.85\% and 33.70\% - were classified in NYHA classes II and III, respectively, while $20.74 \%$ had

Table I Patients' sociodemographic and clinical characteristics $(n=270)$

\begin{tabular}{|c|c|c|}
\hline Characteristic & Mean ( \pm SD) & Median (quartiles) \\
\hline Age (years) & $72.57( \pm 8.23)$ & 71 (66-79) \\
\hline Duration of the illness (years) & $6( \pm 4.76)$ & $4.5(3-7.75)$ \\
\hline LVEF (\%) & $44.64( \pm 11.7)$ & $42(38-54)$ \\
\hline \multirow{2}{*}{$\begin{array}{l}\text { Number of hospitalizations in } \\
\text { the previous year }\end{array}$} & $2.13( \pm 1.69)$ & $2(I-3)$ \\
\hline & $\mathbf{n}$ & $\%$ \\
\hline \multicolumn{3}{|l|}{ Sex } \\
\hline Women & 138 & 51.11 \\
\hline Men & 132 & 48.89 \\
\hline \multicolumn{3}{|l|}{ Residence } \\
\hline Urban & 182 & 67.41 \\
\hline Rural & 88 & 32.59 \\
\hline \multicolumn{3}{|l|}{ Education } \\
\hline Primary or vocational & 133 & 49.26 \\
\hline High school & 90 & 33.33 \\
\hline College/university & 47 & $|7.4|$ \\
\hline \multicolumn{3}{|l|}{ Relationship status } \\
\hline Single & 117 & 43.33 \\
\hline In a relationship & 153 & 56.67 \\
\hline \multicolumn{3}{|l|}{ NYHA class } \\
\hline NYHA I & 10 & 3.70 \\
\hline NYHA II & 113 & 41.85 \\
\hline NYHA III & 91 & 33.70 \\
\hline NYHA IV & 56 & 20.74 \\
\hline \multicolumn{3}{|l|}{ Medication } \\
\hline ACE inhibitors & 174 & 64.44 \\
\hline Diuretics & 227 & 84.07 \\
\hline Glycosides & 57 & 21.11 \\
\hline Beta-blockers & 177 & 65.56 \\
\hline $\mathrm{CCBs}$ & 2 & 0.74 \\
\hline ARBs & 10 & 3.70 \\
\hline
\end{tabular}

Abbreviations: ARBs, angiotensin receptor blockers; ACE inhibitor, angiotensinconverting enzyme inhibitor; CCBs, calcium-channel blockers; LVEF, left ventricular ejection fraction; NYHA, New York Heart Association Functional Classification. 
NYHA class IV. The mean LVEF was $44.64 \%$. Within the previous year, patients were hospitalized 2.13 times on average $( \pm 1.69)$. The mean time from diagnosis was $6( \pm 4.76)$ years.

The most common treatments included ACE inhibitors, used by $64.44 \%$ patients, and diuretics, $84.07 \%$. While $65.56 \%$ of patients were treated with beta-blockers, $21.11 \%$ were treated with glycosides, $3.70 \%$ with ARBs, and $0.74 \%$ with CCBs.

\section{MMSE results}

Analysis of MMSE scores showed that $26.67 \%$ of patients had no dysfunction, $25.19 \%$ had moderate dementia, $18.89 \%$ had mild dementia, $29.26 \%$ had cognitive impairment without dementia, and no respondents had severe dementia.

\section{European Self-care Scale scores}

The respondents' mean score in the self-care scale was 50.39 points $( \pm 25.04)$ out of 100 , ranging between 5.56 and 100 . The median score was 50 points. The first and third quartiles were 27.78 and 66.67 points, respectively, that is, typical scores in the groups studied ranged from 27.78 to 66.67 points.

\section{Does cognitive function, as measured by MMSE,} affect self-care?

Patients with cognitive impairment without dementia and patients with normal MMSE showed significantly better self-care than those with moderate dementia.

\section{Do sociodemographic and clinical variables affect MMSE and self-care scores?}

- Demographic and clinical variables and MMSE

The MMSE scores had a non-normal distribution (Shapiro-Wilk test $p<0.05$ ); thus, Spearman's rank correlation coefficient was used in the analysis. MMSE is significantly affected; values are correlated with higher scores (better cognitive function) in the MMSE questionnaire. Correlations with age, duration of illness, and number of hospitalizations are negative. Thus, older age, longer duration of illness, and higher numbers of hospitalizations are all correlated with lower scores (worse cognitive function) in the MMSE questionnaire. Age was most strongly statistically significantly correlated with MMSE (Table 2).

\section{Variables and EHFScBS- 9}

EHFScBS-9 is significantly affected by all four quantitative variables (Shapiro-Wilk test $p<0.05$ ). The correlation with LVEF is positive, that is higher LVEF values are correlated with higher scores (better self-care) in the EHFScBS-9 questionnaire. Correlations with age, duration of illness, and number of hospitalizations are negative. Thus, older age, longer duration of illness, and higher numbers of hospitalizations are all correlated with lower scores (worse self-care) in the EHFScBS-9 questionnaire. EHFScBS-9 is most strongly correlated with number of hospitalizations (Table 2).

\section{Variables and MMSE scores}

MMSE scores were not normally distributed (Shapiro-Wilk test $p<0.05$ ), and therefore, the Mann-Whitney test (comparison between two groups) or the Kruskal-Wallis test (comparison between more than two groups) was used. The results were presented as medians, quartiles, and ranges for variable values.

Sex, education, relationship status, and NYHA class were significantly associated with MMSE: men had higher MMSE scores (better cognitive function) than women; patients in relationships had higher MMSE scores (better cognitive function) than those living alone.

Post hoc analysis was performed to describe the correlations between MMSE and education and NYHA class in detail. It showed that higher education level is correlated with higher MMSE scores (better cognitive function); lower NYHA class is correlated with higher MMSE scores (better cognitive function).

The remaining sociodemographic and clinical variables do not significantly affect MMSE.

\section{Variables and EHFScBS- 9 scores}

EHFScBS-9 scores did not have normal distributions and, therefore, the Mann-Whitney test (comparison between two

Table 2 Sociodemographic and clinical factors in relation to MMSE and EHFScBS-9 scores $(n=270)$

\begin{tabular}{|c|c|c|c|c|c|c|c|c|}
\hline \multirow[t]{2}{*}{ Factor } & \multicolumn{4}{|c|}{ Correlation with MMSE } & \multicolumn{4}{|c|}{ Correlation with EHFScBS-9 } \\
\hline & CC & $p$-value & CD & CS & CC & $p$-value & CD & CS \\
\hline Age (years) & -0.552 & $<0.001$ & Negative & Moderate & -0.2 & 0.001 & Negative & Very weak \\
\hline Duration of the illness (years) & -0.323 & $<0.001$ & Negative & Weak & -0.131 & 0.032 & Negative & Very weak \\
\hline LVEF (\%) & 0.222 & $<0.001$ & Positive & Very weak & 0.223 & $<0.001$ & Positive & Very weak \\
\hline $\begin{array}{l}\text { Number of hospitalizations in } \\
\text { the previous year }\end{array}$ & -0.268 & $<0.001$ & Negative & Very weak & -0.401 & $<0.001$ & Negative & Weak \\
\hline
\end{tabular}

Abbreviations: CC, correlation coefficient; CD, correlation direction; CS, correlation strength; EHFScBS-9, European Heart Failure Self-care Behavior Scale - nine item; LVEF, left ventricular ejection fraction; MMSE, Mini Mental State Examination. 
groups) or the Kruskal-Wallis test (comparison between more than two groups) was used. The results were shown as medians, quartiles, and ranges for variable values.

Education, relationship status, and NYHA class are statistically significantly associated with EHFScBS-9: respondents in relationships had higher EHFScBS-9 scores (better self-care) than those living alone.

Post hoc analyses were performed to test for associations between EHFScBS-9 and education and NYHA class and showed that higher education level is correlated with higher EHFScBS-9 scores (better self-care), and lower NYHA class is correlated with higher EHFScBS-9 scores (better self-care).

The remaining sociodemographic and clinical variables were not significantly associated with EHFScBS-9.

\section{Multiple regression analysis} Which variables affect MMSE scores?

The linear regression model showed that MMSE is affected $(p<0.05)$ by the EHFScBS-9 score. Each additional point in the EHFSc questionnaire increases the MMSE score by an average of 0.03 points. Each year of life decreases the MMSE score by an average of 0.16 points. Compared to living in a town or city, rural residence increases the MMSE score by an average of 1.27 points. Compared to primary and vocational education, high school education increases the MMSE score by an average of 1.28 points; college/university education increases the MMSE score by an average of 2.19 points. Compared to single status, being in a relationship increases the MMSE score by an average of 1.29 points. Compared to NYHA classes I and II, NYHA IV decreases the MMSE score by an average of 2.31 points (Table 3 ).

\section{Which variables affect EHFScBS-9 scores?}

The linear regression model showed that EHFScBS-9 is affected $(p<0.05)$ by the MMSE score. Each additional point in the MMSE questionnaire increases the EHFScBS-9 score by an average of 0.92 points. The number of hospitalizations in the previous year was statistically significantly associated with EHFScBS-9. Each hospitalization decreases the EHFScBS-9 score by an average of 2.96 points. Compared to women, men have EHFScBS-9 scores lower by 6.72 on

Table 3 Variables affecting MMSE and EHFScBS-9 scores $(n=270)$

\begin{tabular}{|c|c|c|c|c|c|c|c|c|}
\hline \multirow[t]{2}{*}{ Variable } & \multicolumn{4}{|c|}{ Variables affecting MMSE } & \multicolumn{4}{|c|}{ Variables affecting EHFScBS-9 } \\
\hline & Parameter & SE & $\mathbf{t}$ & $p$-value & Parameter & SE & $\mathbf{t}$ & $p$-value \\
\hline EHFScBS-9/MMSE (points) & 0.029 & 0.011 & 2.625 & 0.009 & 0.918 & 0.35 & 2.625 & 0.009 \\
\hline Age (years) & -0.165 & 0.034 & -4.807 & $<0.00 \mathrm{I}$ & 0.076 & 0.201 & 0.377 & 0.706 \\
\hline Duration of the illness (years) & -0.003 & 0.051 & -0.061 & 0.952 & 0.31 & 0.288 & $\mathrm{I} .074$ & 0.284 \\
\hline LVEF (\%) & -0.015 & 0.024 & -0.61 & 0.542 & -0.08 & 0.134 & -0.595 & 0.553 \\
\hline $\begin{array}{l}\text { Number of hospitalizations in } \\
\text { the previous year }\end{array}$ & -0.173 & 0.159 & -1.085 & 0.279 & -2.958 & 0.876 & -3.376 & 0.001 \\
\hline \multicolumn{9}{|l|}{ Sex } \\
\hline \multicolumn{9}{|l|}{ Women - reference } \\
\hline Men & 0.839 & 0.477 & 1.759 & 0.08 & -6.716 & 2.663 & -2.523 & 0.012 \\
\hline \multicolumn{9}{|l|}{ Residence } \\
\hline \multicolumn{9}{|l|}{ Urban - reference } \\
\hline Rural & 1.272 & 0.508 & 2.504 & 0.013 & -1.864 & 2.887 & -0.646 & 0.519 \\
\hline \multicolumn{9}{|l|}{ Education } \\
\hline \multicolumn{9}{|l|}{$\begin{array}{l}\text { Primary or vocational - } \\
\text { reference }\end{array}$} \\
\hline High school & 1.282 & 0.531 & 2.415 & 0.016 & 5.666 & 2.994 & 1.892 & 0.06 \\
\hline College/university & 2.193 & 0.696 & 3.149 & 0.002 & $|2.26|$ & 3.913 & 3.134 & 0.002 \\
\hline \multicolumn{9}{|l|}{ Relationship status } \\
\hline \multicolumn{9}{|l|}{ Single - reference } \\
\hline In a relationship & 1.298 & 0.51 & 2.546 & 0.012 & 9.612 & 2.837 & 3.388 & 0.001 \\
\hline \multicolumn{9}{|l|}{ NYHA class } \\
\hline \multicolumn{9}{|l|}{ NYHA I-II - reference } \\
\hline NYHA III & -0.656 & 0.596 & $-I . I$ & 0.272 & -8.017 & 3.319 & -2.415 & 0.016 \\
\hline NYHA IV & -2.308 & 0.83 & -2.782 & 0.006 & -13.554 & 4.653 & -2.913 & 0.004 \\
\hline
\end{tabular}

Notes: The $\mathrm{R}^{2}$ coefficient for the model was $48.61 \%$, meaning that the variables included in the model account for $48.61 \%$ of variance in MMSE scores; the remaining $51.39 \%$ depends on variables not included in the model or random factors. The $\mathrm{R}^{2}$ coefficient for the model was $40.60 \%$, meaning that the variables included in the model account for $40.60 \%$ of variance in EHFSc scores; the remaining $59.40 \%$ depends on variables not included in the model or random factors.

Abbreviations: EHFScBS-9, European Heart Failure Self-care Behavior Scale - nine item; LVEF, left ventricular ejection fraction; MMSE, Mini Mental State Examination; NYHA, New York Heart Association Functional Classification. 
average. Compared to primary and vocational education, high school education increases the EHFScBS-9 score by an average of 5.66 points; college/university education increases the EHFScBS-9 score by an average of 12.26 points. Being in a relationship increases the EHFScBS-9 score by an average of 9.61 points. Compared to NYHA classes I and II, NYHA III decreases the EHFScBS-9 score by an average of 8.02 points; NYHA IV decreases the EHFScBS-9 score by an average of 13.55 points (Table 3 ).

\section{Discussion}

Normal cognitive functioning is essential in receiving stimuli from one's surroundings and using them to enrich one's intellectual capabilities. Cognitive functions include a number of intellectual processes, such as short-term memory, long-term memory, language processes (writing, reading, and speech), visual and spatial processes, abstract thinking, and perceiving external stimuli. Normal cognitive function allows one to learn, remember, and reproduce information, as well as to communicate it verbally or nonverbally. ${ }^{31}$ It also allows one to solve tasks, plan actions, and make decisions. Overall, full cognitive function enables normal everyday biopsycho-social functioning. Physiologically, aging processes involve age-associated memory impairment or age-related cognitive decline. ${ }^{32}$

This study examined the relationship between cognitive deficits and self-care in a large sample of elderly patients ( $n=270$ ) with HF. Cognitive impairment, as measured with the MMSE questionnaire, was found in $44.07 \%$ of patients, which is consistent with the findings presented by other authors, reporting cognitive impairment in $30 \%-75 \%$ of patients with HF. ${ }^{33-36}$

Previous studies on cognitive function and self-care behaviors in HF exist, but the results were equivocal. These results suggest that only certain self-care activities were compromised in cognitively impaired patients. ${ }^{33,37,38}$ Dickson et $\mathrm{al}^{38}$ suggested that self-care is a decision-making process that uses the prefrontal cortex, and it is not surprising that deficits in memory, attention, and executive function may impair the perception of, interpretation of, and reasoning about early adverse symptoms.

Thus, the present study demonstrated a relationship between cognitive impairment and self-care in elderly HF patients, but also the potential association between age, sex, marital status, and clinical factors such as NYHA class, LVEF, and duration of disease on either cognitive function or self-care. Its results indicate that cognitive impairment, as expected, does affect the self-care capabilities of elderly
HF patients. Interestingly, both MMSE scores and EHFScBS scores were affected by similar factors.

In a study by Antonelli Incalzi et al, ${ }^{39}$ higher NYHA classes were correlated with worse cognitive function, as measured using the MMSE questionnaire, like the present study. Zuccala et $\mathrm{al}^{40}$ evaluated the impact of older age and the LVEF values on cognitive test results and found a close association between LVEF and MMSE scores. Lower ejection fraction values were correlated with worse cognitive function. A similar correlation was found in the present study.

The present study confirmed that, of the variables affecting MMSE scores, age, duration of disease, and the number of rehospitalizations shows the strongest correlations. Age was the most strongly correlated with worsening cognitive functions.

Self-care behaviors were adversely affected by cognitive impairment, higher NYHA classes, and lower LVEF values. The study also indicated that patients have an insufficient self-care level as measured by the EHFScBS scale, because the mean score was 50.3 out of 100 points. Selfcare was negatively affected by older age, longer duration of illness, more hospitalizations, and lack of social support (being single).

Another study showed that only higher scores in the social domains of the frailty scale were correlated with better selfcare capabilities in HF patients. ${ }^{41}$ Self-care capabilities of HF patients, especially with regard to medication, are adversely affected by multimorbidity and polypharmacy. Therefore, the support of family members is of crucial importance in terms of supervising medication and optimizing self-control and self-care among elderly patients with concurrent frailty. ${ }^{41}$

Our findings are consistent with the results of other studies, where several factors have been examined as predictors of adherence to a self-care regimen in patients with HF. Among these were longer duration of disease, better general health knowledge, and better health literacy. ${ }^{37,42}$

In our study, higher education was associated with higher cognitive function and better self-care. Rockwell et al ${ }^{43}$ suggest that better-educated patients may have better selfcare than those with a lower level of education. However, other authors emphasize that a low level of education is not a determinant of self-care ineffectiveness. ${ }^{44,45}$

Findings similar to ours were reported by Hajduk et al, ${ }^{46}$ who examined the associations between impairment in three cognitive domains frequently affected in HF (memory, processing speed, and executive function) and adherence to self-care. They also concluded that cognitive impairment is a common comorbidity of HF that may impact patents' ability 
to perform the self-care behaviors required to maintain their health and prevent hospitalizations. Our research confirms these findings.

\section{Implications for practice}

Based on the results of our study, we would like to highlight the importance of assessing cognitive deficits in elderly patients with $\mathrm{HF}$ in order to promote effective self-care in this patient group. Also, we can highlight two main findings with implications for practice. First of all, self-care strategies may present a significant problem for elderly patients with HF, as they involve behaviors such as taking medication, monitoring and interpreting their symptoms, keeping appointments, and contacting a nurse or a physician in case of exasperation. Secondly, nursing care should be individualized and adjusted to the cognitive capabilities of elderly HF patients, who should be additionally supported by self-care education.

\section{Limitations of the study}

The results of the present study should be interpreted in the context of potential limitations. The most important of these stem from the fact that our study sample was recruited from a single center.

\section{Conclusions}

Elderly patients with HF may have reduced self-care behaviors because of their cognitive deficits. Age was the strongest predictor of worse MMSE scores. Therefore, multidisciplinary health teams should pay attention to the special needs of elderly patients who also live with their illness for a long time and have no social support because of living alone. It is necessary to implement special care in this group of patients, considering their needs related to age.

\section{Acknowledgment}

There was no external source of funding for this research.

\section{Author contributions}

All authors contributed toward data analysis, drafting and revising the paper and agree to be accountable for all aspects of the work.

\section{Disclosure}

The authors report no conflicts of interest in this work.

\section{References}

1. Bui AL, Horwich TB, Fonarow GC. Epidemiology and risk profile of heart failure. Nat Rev Cardiol. 2011;8(1):30-41.
2. Mosterd A, Hoes AW. Clinical epidemiology of heart failure. Heart 2007;93(9):1137-1146.

3. Karasek D, Kubica A, Sinkiewicz W. The epidemic of heart failure health and social problem of aging societies Polish and Europe. Folia Cardiol Excerpta. 2008;3(5):242-248.

4. Pressler SJ. Cognitive functioning and chronic heart failure: a review of the literature (2002-July 2007). J Cardiovasc Nurs. 2008;23(3): 239-249.

5. Adelborg K, Horváth-Puhó E, Ording A, Pedersen L, Toft Sørensen H, Henderson VW. Heart failure and risk of dementia: a Danish nationwide population-based cohort study. Eur J Heart Fail. 2017;19(2): 253-260.

6. Ampadu J, Morley JE. Heart failure and cognitive dysfunction. Int J Cardiol. 2015;178:12-23.

7. Rusanen M, Kivipelto M, Levälahti E, et al. Heart diseases and longterm risk of dementia and Alzheimer's disease: a population-based CAIDE study. J Alzheimers Dis. 2014;42(1):183-191.

8. Cannon JA, McMurray JJ, Quinn TJ. "Hearts and minds": association, causation and implication of cognitive impairment in heart failure. Alzheimers Res Ther. 2015;7(1):22.

9. Leto L, Feola M. Cognitive impairment in heart failure patients. J Geriatr Cardiol. 2014;11(4):316-328.

10. Heckman GA, Patterson CJ, Demers C, St.Onge J, Turpie ID, McKelvie RS. Heart failure and cognitive impairment: challenges and opportunities. Clin Interv Aging. 2007;2(2):209-218.

11. Petrucci RJ, Truesdell KC, Carter A, et al. Cognitive dysfunction in advanced heart failure and prospective cardiac assist device patients. Ann Thorac Surg. 2006;81(5):1738-1744.

12. Kozdağ G, Işeri P, Gökçe G, et al. Treatment with enhanced external counterpulsation improves cognitive functions in chronic heart failure patients. Turk Kardiyol Dern Ars. 2013;41(5):418-428.

13. Alosco ML, Spitznagel MB, Cohen R, et al. Decreased physical activity predicts cognitive dysfunction and reduced cerebral blood flow in heart failure. J Neurol Sci. 2014;339(0):169-175.

14. Glisky EL. Changes in Cognitive Function in Human Aging. In: Riddle DR, ed. Brain Aging: Models, Methods, and Mechanisms. Frontiers in Neuroscience. Boca Raton FL: CRC Press/Taylor \& Francis; 2007. http://www.ncbi.nlm.nih.gov/books/NBK3885/. Accessed March 8, 2017.

15. Riegel B, Carlson B, Moser DK, Sebern M, Hicks FD, Roland V. Psychometric testing of the self-care of heart failure index. $J$ Card Fail. 2004;10(4):350-360.

16. Lainscak M, Blue L, Clark AL, et al. Self-care management of heart failure: practical recommendations from the Patient Care Committee of the Heart Failure Association of the European Society of Cardiology. Eur J Heart Fail. 2011;13(2):115-126.

17. Jaarsma T, Strömberg A, Mårtensson J, Dracup K. Development and testing of the European Heart Failure Self-Care Behaviour Scale. Eur J Heart Fail. 2003;5(3):363-370.

18. Granger BB, Ekman I, Granger CB, et al. Adherence to medication according to sex and age in the CHARM programme. Eur J Heart Fail. 2009;11(11):1092-1098.

19. van der Wal MH, van Veldhuisen DJ, Veeger NJ, Rutten FH, Jaarsma T. Compliance with non-pharmacological recommendations and outcome in heart failure patients. Eur Heart J. 2010;31(12):1486-1493.

20. Riegel B, Vaughan Dickson V, Goldberg LR, Deatrick JA. Factors associated with the development of expertise in heart failure self-care. Nurs Res. 2007;56(4):235-243.

21. Hulley SB, Cummings SR, Browner WS, Grady DG, Newman TB. Designing Clinical Research. 4th ed. Philadelphia: Lippincott Williams and Wilkins; 2013.

22. Folstein MF, Folstein SE, McHugh PR. "Mini-mental state". A practical method for grading the cognitive state of patients for the clinician. J Psychiatr Res. 1975;12(3):189-198.

23. Folstein MF, Folstein SE, McHugh PR, Fanjiang G. Mini-Mental State Examination User's Guide; Odessa, FL, USA: 2001. Odessa, FL: Psychological Assessment Resources, Inc.; 2001. 
24. Uchmanowicz I, Loboz-Rudnicka M, Jaarsma T, Loboz-Grudzień K. Cross-cultural adaptation and reliability testing of Polish adaptation of the European Heart Failure Self-care Behavior Scale (EHFScBS). Patient Prefer Adherence. 2014;8:1521-1526.

25. Uchmanowicz I, Wleklik M. Polish adaptation and reliability testing of the nine-item European Heart Failure Self-care Behaviour Scale (9-EHFScBS). Kardiol Pol. 2016;74(7):691-696.

26. Orem DE. Nursing Concepts of Practice. 6th ed. St Louis: Mosby; 2001.

27. Jaarsma T, Årestedt KF, Mårtensson J, Dracup K, Strömberg A. The European Heart Failure Self-care Behaviour scale revised into a nineitem scale (EHFScB-9): a reliable and valid international instrument. Eur J Heart Fail. 2009;11(1):99-105.

28. Lee CS, Lyons KS, Gelow JM, et al. Validity and reliability of the European Heart Failure Self-care Behavior Scale Among Adults from the United States with Symptomatic Heart Failure. Eur J Cardiovasc Nurs. 2013;12(2):214-218.

29. Köberich S, Glattacker M, Jaarsma T, Lohrmann C, Dassen T. Validity and reliability of the German version of the 9-item European Heart Failure Self-care Behaviour Scale. Eur J Cardiovasc Nurs. 2013;12(2): $150-158$.

30. Hinkle DE, Wiersma W, Jurs SG. Applied Statistics for the Behavioral Sciences. 5th ed. Boston: Houghton Mifflin; 2002.

31. Upadhayay N, Guragain S. Comparison of cognitive functions between male and female medical students: A Pilot Study. J Clin Diagn Res. 2014;8(6):BC12-BC15.

32. Ishizaki T, Yoshida H, Suzuki T, et al. Effects of cognitive function on functional decline among community-dwelling non-disabled older Japanese. Arch Gerontol Geriatr. 2006;42(1):47-58.

33. Cameron J, Worrall-Carter L, Riegel B, Lo SK, Stewart S. Testing a model of patient characteristics, psychologic status, and cognitive function as predictors of self-care in persons with chronic heart failure. Heart Lung. 2009;38(5):410-418.

34. Almeida OP, Flicker L. The mind of a failing heart: a systematic review of the association between congestive heart failure and cognitive functioning. Intern Med J. 2001;31(5):290-295.
35. McLennan SN, Pearson SA, Cameron J, Stewart S. Prognostic importance of cognitive impairment in chronic heart failure patients: does specialist management make a difference? Eur J Heart Fail. 2006;8(5):494-501.

36. Rinaldi P, Mecocci P, Benedetti C, et al. Validation of the five-item geriatric depression scale in elderly subjects in three different settings. J Am Geriatr Soc. 2003;51(5):694-698.

37. Riegel B, Moser DK, Anker SD, et al; American Heart Association Interdisciplinary Council on Quality of Care and Outcomes Research. State of the science: promoting self-care in persons with heart failure: a scientific statement from the American Heart Association. Circulation. 2009; 120(12):1141-1163.

38. Dickson VV, Tkacs N, Riegel B. Cognitive influences on self-care decision making in persons with heart failure. Am Heart J. 2007;154(3): 424-431.

39. Antonelli Incalzi R, Trojano L, Acanfora D, et al; CHF Italian Study Investigators. Verbal memory impairment in congestive heart failure. J Clin Exp Neuropsychol. 2003;25(1):14-23.

40. Zuccalà G, Pedone C, Cesari M, et al. The effects of cognitive impairment on mortality among hospitalized patients with heart failure. Am J Med. 2003;115(2):97-103.

41. Uchmanowicz I, Wleklik M, Gobbens RJJ. Frailty syndrome and selfcare ability in elderly patients with heart failure. Clin Interv Aging. 2015; 10:871-877.

42. Marek KD, Stetzer F, Ryan PA, et al. Nurse care coordination and technology effects on health status of frail older adults via enhanced self-management of medication: randomized clinical trial to test efficacy. Nurs Res. 2013;62(4):269-278.

43. Rockwell JM, Riegel B. Predictors of self-care in persons with heart failure. Heart Lung. 2001;30(1):18-25.

44. Smith B, Forkner E, Krasuski RA, Galbreath AD, Freeman GL. Educational attainment has a limited impact on disease management outcomes in heart failure. Dis Manag. 2006;9(3):157-166.

45. Redman BK. Accountability for patient self-management of chronic conditions; ethical analysis and a proposal. Chronic Illn. 2007;3(1):88-95.

46. Hajduk AM, Lemon SC, McManus DD, et al. Cognitive impairment and self-care in heart failure. Clin Epidemiol. 2013;5:407-416.
Clinical Interventions in Aging

\section{Publish your work in this journal}

Clinical Interventions in Aging is an international, peer-reviewed journal focusing on evidence-based reports on the value or lack thereof of treatments intended to prevent or delay the onset of maladaptive correlates of aging in human beings. This journal is indexed on PubMed Central, MedLine,

\section{Dovepress}

CAS, Scopus and the Elsevier Bibliographic databases. The manuscript management system is completely online and includes a very quick and fair peer-review system, which is all easy to use. Visit http://www.dovepress. com/testimonials.php to read real quotes from published authors. 